\title{
Influence of native lactic acid bacteria on the microbiological, biochemical and sensory profiles of Serra da Estrela cheese
}

\author{
Angela C. Macedo ${ }^{\mathrm{a}, \mathrm{b}}$, Tânia G. Tavares ${ }^{\mathrm{a}}$, F. Xavier Malcata ${ }^{\mathrm{a}, *}$ \\ ${ }^{a}$ Escola Superior de Biotecnologia, Universidade Católica Portuguesa, Rua Dr. António Bernardino de Almeida, P-4200-072 Porto, Portugal \\ ${ }^{\mathrm{b}}$ Instituto Superior da Maia, S. Pedro de Avioso, P-4475-690 Maia, Portugal
}

\begin{abstract}
Cheesemaking from batches of raw ewe's milk was carried out via inoculation with wild strains of Lactococcus lactis subsp. lactis ESB1 10019 and Lactobacillus plantarum ESB5004 independently, or combined with each other. Those two strains had been isolated from the native microflora of typical Serra da Estrela cheese. One control batch was processed in parallel without addition of any starter. The evolution in viable counts of the main micro-organisms (viz. lactic acid bacteria, Enterobacteriaceae, staphylococci and yeasts), as well as in secondary proteolysis (WSN, 2\% TCASN, 12\% TCASN and 5\% PTASN), was monitored throughout ripening time (over a 63-day period) in cheeses from each batch. The sensory features of the fully ripened cheeses were also assessed. Cheeses manufactured with starter showed significantly lower levels of viable Enterobacteriaceae than those manufactured without starter; viable counts of enterococci and staphylococci did significantly increase after addition of $L$. lactis or Lb. plantarum, respectively. Proteolysis in terms of WSN and 5\% PTASN was not significantly affected by the lactic acid bacteria tested when compared to the control, but $L$. lactis played a significant role toward increasing the $2 \%$ TCASN content of cheeses; both strains led to a statistically significant increase of the $12 \%$ TCASN. The scores for flavor and texture of the control cheeses were somewhat above those for the experimental cheeses manufactured with starter.
\end{abstract}

Keywords: Ewe's milk cheese; Starter; Microbiology; Proteolysis; Lipolysis

\section{Introduction}

Serra da Estrela cheese is the most famous variety of farm cheese manufactured in Portugal; the technology associated therewith is unique, in that raw ewe's milk of a native breed (Bordaleira da Serra da Estrela) is coagulated with a plant rennet (Cynara cardunculus, L.) without deliberate addition of any starter culture (Anonymous, 1985; Macedo et al., 1993). Lactic acid bacteria and coliforms are the predominant groups in this cheese, where they eventually reach viable numbers of ca. $10^{7}$ and $10^{5} \mathrm{cfu} / \mathrm{g}$, respectively, by the time of consumption (usually following 45-60 days of ripening); pseudomonads cannot be detected after 7 days of ripening, but staphylococci (ca. $10^{3} \mathrm{cfu} / \mathrm{g}$ ) are still present in cheese by the end of ripening (Macedo et al., 1995; Tavaria and Malcata, 1998).

\footnotetext{
*Corresponding author. Tel.: +351-22-5580004; fax: +351-225090351.

E-mail address: xmalcata@esb.ucp.pt (F.X. Malcata).
}

It has been reported (González-Crespo and Mas, 1993) that widespread use of commercial starter cultures in cheeses manufactured from pasteurized milk results in loss of the typical characteristics that are peculiar to various types of cheese when manufactured from raw milk, because integral replacement of the complex native microbial flora in raw milk by uniform commercial starter cultures leads to blind standardization. Therefore, research efforts should focus on strains that are a part of the microflora originally present in the milk and in the artisan cheeses obtained from it, so as to obtain starter and adjunct starter cultures specifically tailored for addition to thermal treated (or even pasteurized) milk (Puchades et al., 1989; Lee et al., 1990; LitopoulouTzanetaki et al., 1993; Drake et al., 1996; Ortigosa et al., 1999; Mendia et al., 2000).

In view of the aforementioned facts, the goal of this work was to study the effect of three distinct starter cultures obtained from the native microflora of raw milk cheeses, in order to tentatively improve the microbiological quality, and to also mimic the typical chemical and sensory characteristics of Serra da Estrela cheese. 


\section{Materials and methods}

\subsection{Micro-organisms}

Lactobacillus plantarum ESB5004 (BCCM ${ }^{\mathrm{TM}} / \mathrm{LMG}$ ID4916) and Lactococcus lactis subsp. lactis ESB110019 (BCCM ${ }^{\mathrm{TM}} / \mathrm{LMG}$ ID5166), maintained as part of Escola Superior de Biotecnologia's culture collection, were used as starter cultures; these strains had been originally isolated from typical Serra da Estrela cheese (Macedo et al., 2000). Those microorganisms were subcultured twice in M17 and MRS broths, respectively, at $37^{\circ} \mathrm{C}$ overnight; then, they were cultured in sterile $10 \%(\mathrm{w} / \mathrm{v})$ skim milk (Oxoid, Basingstoke, UK) for $16 \mathrm{~h}$ at $37^{\circ} \mathrm{C}$, and mixed with milk immediately before cheese manufacture. (Despite their mesophilic nature, those two strains grow particularly well at $37^{\circ} \mathrm{C}$, so such temperature was selected for incubation for the sake of laboratory space keeping.)

\subsection{Cheesemaking}

Four batches of $141-\mathrm{kg}$ cheeses were prepared in the certified pilot plant of Associação Nacional de Criadores de Ovinos Serra da Estrela (ANCOSE, Oliveira do Hospital, Portugal), under the conditions set forth by the Appéllation d'Origine Controllée legal status. Cheeses were produced from the milk of ewes of Bordaleira da Serra da Estrela breed, in early November.

For each batch, 901 of raw milk was filtered through a fine, clean cloth and poured into a double walled, food grade steel coagulation vat possessing a thermostatted system of water recirculation (Albinox Construções, S. Pedro do Sul, Portugal). After the temperature of the milk had reached $30^{\circ} \mathrm{C}$, starter cultures (or plain sterile $10 \%$ skim milk, used as control) were added and gently mixed with a stirrer. Four different batches were thus prepared: batch LC-raw milk added with $1 \%(\mathrm{v} / \mathrm{v})$ Lactococus lactis ESB110019; batch LB - raw milk added with $1 \% \quad(\mathrm{v} / \mathrm{v})$ Lactobacillus plantarum ESB5004; batch MX - raw milk added with $0.5 \%(\mathrm{v} / \mathrm{v})$ Lactobacillus plantarum ESB5004 and $0.5 \% \quad(\mathrm{v} / \mathrm{v})$ Lactococus lactis ESB110019; and batch CT-raw milk without addition of starter culture (control). Thereafter, crude kitchen salt $(20 \mathrm{~g} / 1$ of milk) and dry thistle flower (Cynara cardunculus L., $0.2 \mathrm{~g} / 1$ of milk) were placed inside a cloth with closed ends, submerged in the milk, hand-macerated and agitated, and squeezed until complete solubilization of the salt. The milk was then allowed to rest at $32^{\circ} \mathrm{C}$ until coagulation had occurred (ca. $45 \mathrm{~min}$ ); this state was empirically assessed by the cheesemaker via observation of the consistency of the curd upon a gentle surface cut. The coagulum was then fully cut by stirring it with $20 \times 20 \mathrm{~mm}^{2}$ knives (Albinox). Ten minutes later, the curd pieces were poured into a fine cloth bag, which was duly closed and firmly pressed so as to help in the expression of whey. Each cheese was surface labeled using a food-grade casein marker (Gist Brocades, Delft, The Netherlands). Drainage of whey was completed via pressing the fresh cheese, while in the plastic perforated mould, via a standard pneumatic press (Albinox). The cheeses were then placed in a first ripening room, with temperature controlled at $8-9^{\circ} \mathrm{C}$ and relative humidity controlled at $95 \%$, and were turned upside down daily for a preliminary ripening period of 20 days. Afterwards, the cheeses were washed with warm water in order to remove the reddish surface smear, and a band of cotton cloth was wound around each cheese and tied up with a small knot. At this time, the cheeses were moved to a second maturation room, with temperature controlled at $10-12^{\circ} \mathrm{C}$ and relative humidity controlled at $85 \%$, for a second and final ripening period.

Cheeses from each batch were randomly taken, during the ripening period, by $0,2,4,7,14,28,42$ and 63 days, and transported under refrigerated conditions (ca. $4^{\circ} \mathrm{C}$ ) to our laboratory premises for analysis. True replicates of $0,4,14$ and 42-day-old cheeses were also analysed.

\subsection{Microbiological analyses}

Cheese homogenates and decimal dilutions thereof, as well as plating procedures and enumeration of such micro-organisms as lactococci (M17 agar), lactobacilli (Rogosa agar), enterococci (Kanamycin aesculin agar), Enterobacteriaceae (Violet red bile glucose agar), staphylococci (Baird-Parker medium) and yeasts (Potato dextrose agar) were conducted as described previously (Macedo et al., 1995). All media were purchased from LabM (Bury, UK).

\subsection{Physicochemical analyses}

The $\mathrm{pH}$ of cheese samples was determined directly using a MicropH 2001 (Crison, Barcelona, Spain); the dry matter content was determined by the oven (Ehret, Emmendingen, Germany) method at $102^{\circ} \mathrm{C}$ for $24 \mathrm{~h}$; the salt content was determined by the modified Volhard method; the fat content was determined by the Gerbervan Gulik method, using a NormMilk centrifuge (International PVI, Milano, Italy); and the total nitrogen content was determined by the micro-Kjeldahl method (IDF, 1993), using a Kjeltec system with a 2012 digester and a 1002 distilling unit (Tecator, Hoganas, Sweden).

Fractionations with water, with $2 \%$ and $12 \%(\mathrm{w} / \mathrm{v})$ trichloroacetic acid (TCA), and with $5 \%(\mathrm{w} / \mathrm{v})$ phosphotungstic acid (PTA) were done according to Macedo and Malcata (1997a). The nitrogen contents of all these fractions were also determined by the micro-Kjeldhal method. 
All reagents needed to carry out the chemical analyses were supplied by Merck (Darmstad, Germany), and were employed as such without further purification.

\subsection{Sensory analyses}

A taste panel, consisting of five-trained judges (from the permanent staff of the official panel for Serra da Estrela cheese certification), evaluated the experimental cheeses using a hedonic discrete scale, namely the rind $(0-4)$, the shape and consistency $(0-4)$, the texture and color of the paste (0-6), and the taste and aroma of the paste (0-6), according to the Portuguese Standard 1922 (Anonymous, 1985). The duplicates of the four types of 63-day-old cheeses were evaluated in the same panel session. Description of the defects encountered was also recorded.

\subsection{Statistical analyses}

The results from the randomized experimental design, encompassing microbiological and physicochemical data, were submitted to analysis of variance at the $5 \%$ level of significance, using as independent factors ripening time $(0,2,4,7,14,28,42$ and 63 days) and starter culture (LC, LB, MX and CT). Additionally, multiple comparisons were carried out using Bonferroni's test, also at the $5 \%$ level of significance, between microbiological and physicochemical data among the various ripening times for a given starter culture, and among the various starter cultures for each ripening time. Data on sensory analyses were submitted to ANOVA using the starter cultures as independent factor, and Student's paired $t$-test was also applied.

All analyses were performed using the SPSS statistical package (version 10.1 SPSS, Chicago, IL, USA).

\section{Results}

The logarithmic counts of the micro-organisms enumerated throughout ripening time for the various experimental and control cheeses are depicted in Table 1. The factors ripening time and starter culture affected to a significant extent $(P<0.05)$ the numbers of all micro-organisms tested in cheese (ANOVA results not shown); one exception to this general trend was the case of staphylococci counts, which were not affected $(P=0.06)$ by ripening time. Lactococci in the LC cheeses exhibited the highest log counts values throughout ripening time, and passed through an earlier decrease after the maximum log count had been reached than in LB or MX cheeses (the behaviors of which were similar to each other). The main differences in the profiles of viable counts of lactobacilli between LB cheeses, on the one hand, and LC and CT cheeses, on the other, were a significantly higher maximum value reached by 14 days in the former, and the slowest decrease of the viable numbers of lactobacilli after that initial period. The lactobacilli profile in the MX cheeses throughout ripening time was intermediate between those in the LB and LC cheeses. The behaviors of enterococci throughout ripening time in the four types of experimental cheeses were essentially identical to each other; however, the ripened LC cheeses exhibited significantly higher numbers of enterococci than the LB, MX and CT cheeses. Although the evolution pattern of the log counts of Enterobacteriaceae throughout ripening time in the four types of cheese tested were similar, our results indicate that lactic acid bacteria intentionally added to milk affected significantly the time necessary to reach the maximum value of $\log$ counts (i.e. 7, 4, 2 and 14 days of ripening for the LC, LB, MX and CT cheeses, respectively). The log count of Enterobacteriaceae in 63day-old MX cheese was significantly lower $(P<0.05)$ than that obtained in the CT cheese with the same age, but statistically identical to those obtained in the LC and LB cheeses. On the other hand, the log count of staphylococci in the 63-day-old CT cheese was significantly lower (by ca. $0.5,1.6$ and $0.8 \mathrm{log}$ ) than in the experimental cheeses (LC, LB and MX, respectively). Finally, one observed that the log counts of yeasts were statistically highest in the MX and LB cheeses, and lowest in the CT cheese.

The compositions of the LC, LB, MX and CT cheeses are shown in Table 2. There were no statistical differences $(P>0.05)$ in the moisture content and in the percentage (dry matter basis) of fat, total nitrogen and salt among the four types of cheese and throughout ripening time. The $\mathrm{pH}$ of $\mathrm{LC}$ cheeses was significantly lower in 0 and 2-day-old cheeses than in LB, MX and $\mathrm{CT}$ cheeses of the same age, and was significantly lower in 4-day-old LB and CT cheeses.

Evolution of proteolysis in terms of nitrogen soluble in water, in $2 \%$ TCA, in $12 \%$ TCA and in 5\% PTA throughout ripening time is presented in Table 3 . There was no statistical difference between the WSN or $5 \%$ PTASN contents of the experimental and control cheeses. However, the 42- and 63-day-old LC cheeses presented significantly higher $(P<0.05)$ contents of $2 \%$ TCASN than the LB, MX and CT cheeses. Additionally, the contents of $12 \%$ TCASN increased significantly only at the final stage of ripening (i.e. after 28 days), when the contents of $12 \%$ TCASN in the LC and LB cheeses were significantly higher than those in the MX and CT cheeses.

The overall sensory evaluation of cheeses manufactured with starter (see Table 4) indicated that they were statistically similar to each other, but surprisingly lower than that of the control cheeses $(P<0.05)$. Additionally, $\mathrm{CT}$ cheeses presented a better rind (i.e. well formed and clean) and a better shape (i.e. a slightly deformed shape 
Table 1

Evolution (mean \pm standard deviation for replicated data or actual value for unreplicated data, in $\log$ cfu/g) of total viable micro-organisms, lactococci, lactobacilli, enterococci, Enterobacteriaceae, staphylococci and yeasts throughout ripening time, for each of the four types of starter addition

\begin{tabular}{|c|c|c|c|c|c|c|c|}
\hline Time (days) & Culture type ${ }^{a}$ & Lactococci & Lactobacilli & Enterococci & Enterobacteriaceae & Staphylococci & Yeasts \\
\hline \multirow[t]{4}{*}{0} & $\mathrm{LC}$ & $9.10 \pm 0.06$ & $7.79 \pm 0.07$ & $6.43 \pm 0.11$ & $7.38 \pm 0.17$ & $6.23 \pm 0.01$ & $3.91 \pm 0.19$ \\
\hline & LB & $8.34 \pm 0.22$ & $7.24 \pm 0.09$ & $5.92 \pm 0.25$ & $7.46 \pm 0.02$ & $6.38 \pm 0.03$ & $3.65 \pm 0.24$ \\
\hline & MX & $8.31 \pm 0.07$ & $7.57 \pm 0.04$ & $5.18 \pm 0.09$ & $6.92 \pm 0.19$ & $5.18 \pm 0.09$ & $3.00 \pm 0.01$ \\
\hline & $\mathrm{CT}$ & $7.17 \pm 0.07$ & $5.76 \pm 0.08$ & $5.45 \pm 0.14$ & $6.92 \pm 0.03$ & $7.12 \pm 0.08$ & $3.77 \pm 0.10$ \\
\hline \multirow[t]{4}{*}{2} & $\mathrm{LC}$ & 9.70 & 8.40 & 6.70 & 7.80 & 6.41 & 4.06 \\
\hline & LB & 8.65 & 8.30 & 7.26 & 8.13 & 6.86 & 4.23 \\
\hline & MX & 8.60 & 8.00 & 6.36 & 7.65 & 6.26 & 4.15 \\
\hline & $\mathrm{CT}$ & 8.40 & 7.40 & 7.08 & 8.37 & 7.38 & 3.93 \\
\hline \multirow[t]{4}{*}{4} & LC & $10.80 \pm 0.14$ & $8.62 \pm 0.36$ & $8.11 \pm 0.05$ & $8.12 \pm 0.22$ & $6.47 \pm 0.07$ & $4.37 \pm 0.07$ \\
\hline & LB & $9.29 \pm 0.16$ & $8.92 \pm 0.02$ & $7.62 \pm 0.04$ & $8.32 \pm 0.10$ & $7.36 \pm 0.15$ & $4.51 \pm 0.75$ \\
\hline & MX & $9.03 \pm 0.07$ & $8.78 \pm 0.01$ & $7.18 \pm 0.07$ & $7.15 \pm 0.09$ & $7.18 \pm 0.07$ & $5.14 \pm 0.03$ \\
\hline & $\mathrm{CT}$ & $8.70 \pm 0.01$ & $8.56 \pm 0.08$ & $7.39 \pm 0.01$ & $8.27 \pm 0.03$ & $7.94 \pm 0.18$ & $3.94 \pm 0.02$ \\
\hline \multirow[t]{4}{*}{7} & $\mathrm{LC}$ & 11.48 & 9.67 & 8.30 & 8.45 & 6.59 & 4.90 \\
\hline & LB & 10.40 & 10.00 & 7.51 & 7.79 & 7.74 & 5.29 \\
\hline & MX & 10.58 & 9.00 & 7.32 & 7.00 & 7.19 & 5.90 \\
\hline & $\mathrm{CT}$ & 9.22 & 9.06 & 8.04 & 8.51 & 7.18 & 4.02 \\
\hline \multirow[t]{4}{*}{14} & LC & $10.64 \pm 0.03$ & $9.21 \pm 0.01$ & $7.72 \pm 0.49$ & $8.14 \pm 0.05$ & $6.45 \pm 0.01$ & $5.17 \pm 0.06$ \\
\hline & LB & $10.13 \pm 0.18$ & $10.57 \pm 0.18$ & $7.36 \pm 0.07$ & $6.95 \pm 0.24$ & $7.35 \pm 0.06$ & $6.00 \pm 0.31$ \\
\hline & MX & $10.36 \pm 0.07$ & $10.00 \pm 0.09$ & $7.18 \pm 0.10$ & $6.66 \pm 0.06$ & $7.13 \pm 0.02$ & $6.16 \pm 0.09$ \\
\hline & $\mathrm{CT}$ & $9.16 \pm 0.01$ & $9.28 \pm 0.10$ & $7.76 \pm 0.03$ & $8.73 \pm 0.17$ & $6.65 \pm 0.02$ & $4.31 \pm 0.04$ \\
\hline \multirow[t]{4}{*}{28} & $\mathrm{LC}$ & 10.40 & 8.74 & 8.38 & 6.92 & 6.30 & 5.23 \\
\hline & LB & 9.24 & 10.30 & 7.32 & 6.38 & 7.37 & 5.38 \\
\hline & MX & 9.50 & 9.11 & 7.65 & 5.90 & 6.33 & 5.67 \\
\hline & $\mathrm{CT}$ & 8.85 & 8.86 & 8.06 & 7.62 & 6.61 & 4.27 \\
\hline \multirow[t]{4}{*}{42} & $\mathrm{LC}$ & $10.08 \pm 0.11$ & $8.20 \pm 0.12$ & $8.15 \pm 0.08$ & $6.45 \pm 0.21$ & $6.22 \pm 0.01$ & $5.00 \pm 0.14$ \\
\hline & LB & $8.82 \pm 0.22$ & $10.22 \pm 0.11$ & $7.55 \pm 0.21$ & $5.90 \pm 0.04$ & $7.34 \pm 0.01$ & $5.07 \pm 0.01$ \\
\hline & MX & $9.17 \pm 0.26$ & $8.55 \pm 0.02$ & $6.71 \pm 0.09$ & $5.31 \pm 0.08$ & $6.48 \pm 0.05$ & $5.86 \pm 0.14$ \\
\hline & $\mathrm{CT}$ & $9.03 \pm 0.07$ & $7.93 \pm 0.07$ & $7.56 \pm 0.16$ & $6.77 \pm 0.29$ & $6.60 \pm 0.04$ & $4.13 \pm 0.08$ \\
\hline \multirow[t]{4}{*}{63} & $\mathrm{LC}$ & 8.78 & 7.60 & 8.27 & 4.61 & 6.10 & 4.70 \\
\hline & LB & 7.68 & 9.57 & 7.32 & 4.95 & 7.33 & 4.30 \\
\hline & MX & 6.27 & 8.30 & 6.50 & 4.38 & 6.56 & 4.74 \\
\hline & $\mathrm{CT}$ & 8.06 & 7.13 & 6.98 & 5.15 & 5.74 & 4.08 \\
\hline
\end{tabular}

${ }^{\mathrm{a}}$ LC - cheese added with 1\% Lactococcus lactis ESB110019; LB - cheese added with 1\% Lactobacillus plantarum ESB5004; MX - cheese added with $0.5 \%$ Lactobacillus plantarum ESB5004 and $0.5 \%$ Lactococcus lactis ESB110019; and CT-cheese without addition of any starter culture.

on the side surfaces) than the LC, LB and MX cheeses. However, the CT cheeses exhibited a more buttery texture and less acid and bitter flavors than the LC cheeses, but a flavor similar to that of the LB cheeses.

\section{Discussion}

Although counts are in general high at startup of ripening, note that our findings are consistent with evidence made available elsewhere (Macedo et al., 1995; Tavaria and Malcata, 1998). In addition, increase in the viable counts of lactococci and lactobacilli up to 4 days is a consequence not only of growth thereof during that initial period, but mainly to concentration in the curd.

The deliberate addition of L. lactis in Serra da Estrela cheese indicated that lactococci at high viable levels (i.e. above $10 \log \mathrm{cfu} / \mathrm{g}$ ) inhibit their own growth as a probable consequence of the drastic reduction in $\mathrm{pH}$ caused thereby (as discussed below); similar observations were reported (Ortigosa et al., 1999) for Idiazábal and Roncal ewe's cheeses. On the other hand, deliberate addition of $L b$. plantarum to this type of cheese indicated that lactobacilli survive better in cheeses where their viable counts are similar to, or even higher than those of lactococci; in this case, a lower $\mathrm{pH}$ did not accelerate death of lactobacilli. The growth of entero- 
Table 2

Evolution (mean \pm standard deviation for replicated data or actual value for unreplicated data) of contents of moisture, fat, total nitrogen and salt, and of $\mathrm{pH}$ throughout the ripening time, for each of the four types of starter addition

\begin{tabular}{|c|c|c|c|c|c|c|}
\hline $\begin{array}{l}\text { Time } \\
\text { (days) }\end{array}$ & $\begin{array}{l}\text { Starter } \\
\text { culture }^{\mathrm{a}}\end{array}$ & $\begin{array}{l}\text { Moisture, } \% \\
\left(\mathrm{w} / \mathrm{w}_{\text {cheese }}\right)\end{array}$ & $\begin{array}{l}\text { Fat, } \% \\
\left(\mathrm{w} / \mathrm{w}_{\mathrm{DM}} \text { of cheese }\right)\end{array}$ & $\begin{array}{l}\text { Total nitrogen, } \% \\
\left(\mathrm{w} / \mathrm{w}_{\mathrm{DM}} \text { of cheese }\right)\end{array}$ & $\begin{array}{l}\text { Salt, } \% \\
\left(\mathrm{w} / \mathrm{w}_{\mathrm{DM}} \text { of cheese }\right)\end{array}$ & $\mathrm{pH}$ \\
\hline \multirow[t]{4}{*}{0} & $\mathrm{LC}$ & $52.99 \pm 0.89$ & $56.28 \pm 2.57$ & $5.52 \pm 0.30$ & $1.72 \pm 0.07$ & $6.05 \pm 0.04$ \\
\hline & LB & $51.75 \pm 0.17$ & $51.55 \pm 0.16$ & $5.83 \pm 0.63$ & $1.81 \pm 0.17$ & $6.31 \pm 0.02$ \\
\hline & MX & $51.36 \pm 0.24$ & $51.40 \pm 0.98$ & $5.63 \pm 0.33$ & $2.03 \pm 0.05$ & $6.30 \pm 0.02$ \\
\hline & $\mathrm{CT}$ & $53.63 \pm 0.16$ & $55.81 \pm 2.10$ & $5.63 \pm 0.21$ & $1.46 \pm 0.17$ & $6.37 \pm 0.01$ \\
\hline \multirow[t]{4}{*}{2} & $\mathrm{LC}$ & 50.66 & 57.77 & 5.32 & 1.45 & 5.58 \\
\hline & LB & 51.30 & 52.88 & 5.74 & 1.49 & 5.87 \\
\hline & MX & 50.89 & 52.34 & 5.68 & 1.55 & 5.82 \\
\hline & $\mathrm{CT}$ & 51.47 & 54.61 & 5.64 & 1.87 & 6.18 \\
\hline \multirow[t]{4}{*}{4} & $\mathrm{LC}$ & $49.59 \pm 0.13$ & $54.29 \pm 1.07$ & $4.76 \pm 0.55$ & $1.86 \pm 0.12$ & $5.42 \pm 0.01$ \\
\hline & LB & $50.39 \pm 0.03$ & $52.87 \pm 0.75$ & $5.74 \pm 0.32$ & $1.36 \pm 0.21$ & $5.68 \pm 0.07$ \\
\hline & MX & $50.33 \pm 0.22$ & $52.99 \pm 2.40$ & $5.71 \pm 0.40$ & $1.66 \pm 0.33$ & $5.40 \pm 0.02$ \\
\hline & $\mathrm{CT}$ & $50.38 \pm 0.30$ & $51.88 \pm 2.53$ & $6.01 \pm 0.86$ & $1.36 \pm 0.03$ & $5.93 \pm 0.02$ \\
\hline \multirow[t]{4}{*}{7} & $\mathrm{LC}$ & 48.95 & 55.83 & 5.92 & 2.07 & 5.27 \\
\hline & LB & 50.12 & 52.17 & 5.68 & 1.52 & 5.20 \\
\hline & MX & 49.89 & 53.88 & 6.46 & 1.76 & 5.28 \\
\hline & $\mathrm{CT}$ & 49.72 & 54.69 & 5.55 & 1.96 & 5.65 \\
\hline \multirow[t]{4}{*}{14} & $\mathrm{LC}$ & $48.43 \pm 0.21$ & $56.48 \pm 0.58$ & $5.60 \pm 0.12$ & $2.08 \pm 0.23$ & $5.14 \pm 0.00$ \\
\hline & LB & $49.47 \pm 0.42$ & $52.44 \pm 0.96$ & $5.74 \pm 0.15$ & $1.71 \pm 0.39$ & $5.07 \pm 0.03$ \\
\hline & MX & $49.72 \pm 0.13$ & $53.77 \pm 0.87$ & $5.85 \pm 0.39$ & $1.66 \pm 0.53$ & $5.11 \pm 0.04$ \\
\hline & $\mathrm{CT}$ & $49.02 \pm 0.41$ & $51.54 \pm 1.76$ & $5.58 \pm 0.90$ & $1.60 \pm 0.51$ & $5.40 \pm 0.04$ \\
\hline \multirow[t]{4}{*}{28} & $\mathrm{LC}$ & 48.44 & 55.76 & 5.31 & 2.10 & 4.81 \\
\hline & LB & 49.19 & 54.92 & 5.50 & 1.85 & 4.62 \\
\hline & MX & 48.94 & 52.88 & 5.83 & 2.26 & 4.88 \\
\hline & $\mathrm{CT}$ & 49.00 & 55.90 & 5.82 & 2.01 & 5.23 \\
\hline \multirow[t]{4}{*}{42} & $\mathrm{LC}$ & $46.82 \pm 0.38$ & $55.25 \pm 1.51$ & $5.06 \pm 0.08$ & $1.31 \pm 0.22$ & $4.79 \pm 0.01$ \\
\hline & LB & $49.11 \pm 0.15$ & $55.34 \pm 1.44$ & $5.52 \pm 0.45$ & $1.49 \pm 0.07$ & $4.66 \pm 0.07$ \\
\hline & MX & $48.76 \pm 0.35$ & $54.41 \pm 1.01$ & $5.69 \pm 0.01$ & $1.99 \pm 0.03$ & $4.75 \pm 0.07$ \\
\hline & $\mathrm{CT}$ & $48.43 \pm 0.36$ & $53.57 \pm 1.99$ & $4.51 \pm 0.49$ & $1.41 \pm 0.10$ & $5.24 \pm 0.04$ \\
\hline \multirow[t]{4}{*}{63} & $\mathrm{LC}$ & 45.60 & 58.36 & 5.02 & 2.01 & 4.85 \\
\hline & LB & 47.91 & 53.19 & 5.80 & 2.24 & 4.98 \\
\hline & MX & 48.89 & 55.38 & 6.33 & 1.61 & 4.74 \\
\hline & $\mathrm{CT}$ & 47.96 & 55.14 & 4.20 & 1.34 & 5.50 \\
\hline
\end{tabular}

${ }^{\mathrm{a}}$ LC - cheese added with 1\% Lactococcus lactis ESB110019; LB — cheese added with 1\% Lactobacillus plantarum ESB5004; MX - cheese added with $0.5 \%$ Lactobacillus plantarum ESB5004 and $0.5 \%$ Lactococcus lactis ESB110019; and CT-cheese without addition of any starter culture.

cocci was promoted by the presence of $L$. lactis relative to $L b$. plantarum; this is so because enterococci probably resist better in cheeses with a larger lactic acidproducing population and/or a lower $\mathrm{pH}$. Ortigosa et al. (1999) reported similar findings based on the fact that enterococci exhibit greater resistance owing to microbiological antagonism of bacteria that make up the starter culture with other bacterial genera (hence allowing a slighter reduction of enterococcus viable numbers). The effect of lactic acid bacteria towards reduction of the numbers of Enterobacteriaceae can be rationalized based on the fact that survival of this family in cheese is related to $\mathrm{pH}$ (especially at $\mathrm{pH}$ values not above 5.0) (Rutzinski et al., 1979) and to antimicrobial compounds produced by lactic acid bacteria (Rash and Kosikowski, 1981; El Soda et al., 2000). In Serra da Estrela cheese, the combination of $L$. lactis and $L b$. plantarum seems to be the best option toward controlling growth of Enterobacteriaceae - similar observations were reported by Rash and Kosikowski (1981), as well as in producing final cheeses bearing lower counts of these bacteria, as deemed necessary in attempts to improve the microbiological quality of this cheese. Unlike the effect of $L$. lactis and $L b$. plantarum on Enterobacteriace, the results indicated that the lactic acid bacteria deliberately added to milk did not 
Table 3

Evolution (mean \pm standard deviation for replicated data or actual value for unreplicated data) of nitrogen soluble in water (WSN), in $2 \%$ trichloroacetic acid $(2 \%$ TCASN), in $12 \%$ trichloroacetic acid $(12 \%$ TCASN) and in $5 \%$ phosphotungstic acid (5\% PTASN) throughout the ripening time, for each of the four types of starter addition

\begin{tabular}{|c|c|c|c|c|c|}
\hline $\begin{array}{l}\text { Time } \\
\text { (days) }\end{array}$ & Culture type $^{\mathrm{a}}$ & $\begin{array}{l}\text { WSN, } \% \\
\left(\mathrm{w} / \mathrm{w}_{\mathrm{TN}} \text { of cheese DM }\right)\end{array}$ & $\begin{array}{l}2 \% \text { TCASN, } \% \\
\left(\mathrm{w} / \mathrm{w}_{\mathrm{TN}} \text { of cheese } \mathrm{DM}\right)\end{array}$ & $\begin{array}{l}12 \% \text { TCASN, } \% \\
\left(\mathrm{w} / \mathrm{w}_{\mathrm{TN}} \text { of cheese DM }\right)\end{array}$ & $\begin{array}{l}5 \% \text { PTASN, } \% \\
\left(\mathrm{w} / \mathrm{w}_{\mathrm{TN}} \text { of cheese } \mathrm{DM}\right)\end{array}$ \\
\hline \multirow[t]{4}{*}{0} & $\mathrm{LC}$ & $11.10 \pm 2.97$ & $4.63 \pm 0.79$ & $1.78 \pm 0.18$ & $0.66 \pm 0.12$ \\
\hline & LB & $10.33 \pm 3.14$ & $4.21 \pm 1.08$ & $2.24 \pm 0.22$ & $0.78 \pm 0.01$ \\
\hline & MX & $16.18 \pm 4.25$ & $4.74 \pm 0.33$ & $1.96 \pm 0.12$ & $0.42 \pm 0.05$ \\
\hline & CT & $10.74 \pm 1.95$ & $4.29 \pm 0.49$ & $1.51 \pm 0.07$ & $0.71 \pm 0.02$ \\
\hline \multirow[t]{4}{*}{2} & $\mathrm{LC}$ & 12.08 & 4.97 & 2.23 & 0.66 \\
\hline & LB & 12.73 & 6.19 & 3.25 & 0.42 \\
\hline & MX & 14.77 & 5.98 & 1.76 & 0.20 \\
\hline & CT & 11.02 & 4.57 & 1.66 & 0.60 \\
\hline \multirow[t]{4}{*}{4} & $\mathrm{LC}$ & $13.50 \pm 3.68$ & $5.68 \pm 0.71$ & $2.46 \pm 0.42$ & $0.50 \pm 0.10$ \\
\hline & LB & $15.93 \pm 2.96$ & $5.56 \pm 1.20$ & $2.63 \pm 0.42$ & $0.63 \pm 0.12$ \\
\hline & MX & $13.90 \pm 1.10$ & $5.78 \pm 0.39$ & $2.32 \pm 0.04$ & $0.23 \pm 0.08$ \\
\hline & $\mathrm{CT}$ & $15.53 \pm 0.90$ & $5.01 \pm 0.74$ & $1.84 \pm 0.57$ & $0.57 \pm 0.09$ \\
\hline \multirow[t]{4}{*}{7} & $\mathrm{LC}$ & 14.64 & 7.62 & 3.06 & 0.52 \\
\hline & $\mathrm{LB}$ & 17.47 & 6.19 & 3.25 & 0.42 \\
\hline & MX & 18.37 & 6.27 & 1.88 & 0.25 \\
\hline & $\mathrm{CT}$ & 17.50 & 5.47 & 2.08 & 0.61 \\
\hline \multirow[t]{4}{*}{14} & $\mathrm{LC}$ & $20.85 \pm 1.97$ & $8.92 \pm 0.98$ & $3.68 \pm 0.16$ & $0.48 \pm 0.05$ \\
\hline & LB & $22.21 \pm 1.09$ & $8.13 \pm 0.48$ & $3.47 \pm 0.32$ & $0.46 \pm 0.02$ \\
\hline & MX & $21.02 \pm 1.77$ & $6.85 \pm 0.64$ & $2.50 \pm 0.89$ & $0.37 \pm 0.06$ \\
\hline & $\mathrm{CT}$ & $24.19 \pm 4.32$ & $7.64 \pm 0.50$ & $2.81 \pm 0.26$ & $0.52 \pm 0.09$ \\
\hline \multirow[t]{4}{*}{28} & $\mathrm{LC}$ & 22.45 & 12.79 & 6.10 & 0.56 \\
\hline & LB & 26.13 & 11.91 & 5.04 & 0.49 \\
\hline & MX & 27.24 & 7.74 & 4.03 & 0.47 \\
\hline & $\mathrm{CT}$ & 30.64 & 8.74 & 3.07 & 0.56 \\
\hline \multirow[t]{4}{*}{42} & $\mathrm{LC}$ & $28.81 \pm 3.54$ & $18.78 \pm 0.61$ & $6.57 \pm 1.49$ & $0.53 \pm 0.16$ \\
\hline & LB & $32.46 \pm 4.24$ & $12.13 \pm 0.57$ & $6.01 \pm 0.60$ & $0.62 \pm 0.02$ \\
\hline & MX & $34.06 \pm 2.69$ & $10.68 \pm 0.56$ & $4.61 \pm 0.18$ & $0.47 \pm 0.01$ \\
\hline & $\mathrm{CT}$ & $43.21 \pm 4.01$ & $12.52 \pm 1.68$ & $4.69 \pm 0.83$ & $0.58 \pm 0.14$ \\
\hline \multirow[t]{4}{*}{63} & $\mathrm{LC}$ & 48.54 & 27.85 & 9.64 & 1.04 \\
\hline & LB & 48.09 & 17.15 & 8.62 & 0.90 \\
\hline & MX & 43.13 & 13.07 & 5.93 & 0.68 \\
\hline & $\mathrm{CT}$ & 59.17 & 18.25 & 6.77 & 0.74 \\
\hline
\end{tabular}

${ }^{\mathrm{a}}$ LC — cheese added with 1\% Lactococcus lactis ESB110019; LB — cheese added with 1\% Lactobacillus plantarum ESB5004; MX — cheese added with $0.5 \%$ Lactobacillus plantarum ESB5004 and 0.5\% Lactococcus lactis ESB110019; and CT-cheese without addition of any starter culture.

Table 4

Sensory attributes (mean \pm standard deviation for replicated data) of 63-day-old cheeses

\begin{tabular}{llllll}
\hline Culture type $^{\mathrm{a}}$ & Rind $(0-4)$ & Shape $(0-4)$ & Texture $(0-6)$ & Flavor $(0-6)$ & Global $(0-20)$ \\
\hline LC & $2.7 \pm 0.4$ & $2.7 \pm 0.3$ & $3.9 \pm 0.4$ & $3.2 \pm 0.5$ & $12.5 \pm 0.9$ \\
LB & $2.7 \pm 0.3$ & $2.7 \pm 0.3$ & $3.7 \pm 0.3$ & $4.1 \pm 0.4$ & $13.2 \pm 1.0$ \\
MX & $2.6 \pm 0.2$ & $2.6 \pm 0.2$ & $3.3 \pm 0.3$ & $3.2 \pm 0.6$ & $11.7 \pm 0.8$ \\
CT & $3.0 \pm 0.4$ & $3.3 \pm 0.3$ & $4.4 \pm 0.4$ & $4.0 \pm 0.6$ & $14.7 \pm 0.9$ \\
\hline
\end{tabular}

${ }^{\mathrm{a}} \mathrm{LC}$ - cheese added with 1\% Lactococcus lactis ESB110019; LB — cheese added with 1\% Lactobacillus plantarum ESB5004; MX - cheese added with $0.5 \%$ Lactobacillus plantarum ESB5004 and 0.5\% Lactococcus lactis ESB110019; and CT-cheese without addition of any starter culture.

reduce significantly the numbers of staphylococci in cheeses as intended; instead, the presence of $L$. lactis and Lb. plantarum (especially the latter) did not inhibit the growth, and even lowered the death rate of these bacteria when compared with what happens with the CT cheeses. Gaya et al. (1988) reported that survival of 
staphyloccocci is influenced by other factors than solely cheese $\mathrm{pH}$, viz. redox potential and inhibitory substances present other than lactic acid.

The results obtained for composition were within the limits already reported for Serra da Estrela cheese (Macedo and Malcata, 1997a). Addition of lactic acid starter to milk influences the rate of decrease of $\mathrm{pH}$ during ripening, and the final $\mathrm{pH}$ levels reached in the cheeses; L. lactis was more efficient than Lb. plantarum in decreasing the $\mathrm{pH}$ of cheese at initial stages of ripening. Note that a final $\mathrm{pH}$ of 4.74 is acceptable for this cheese (Macedo et al., 1996; Macedo and Malcata, 1997a); hence, this work has put an emphasis on the production of lactic acid, especially because comments on extra acid mouthfeel were put forward by the panelists when tasting the experimental cheeses.

The profiles and values of WSN, 2\% TCASN, $12 \%$ TCASN and 5\% PTNSN in control cheeses throughout ripening were similar to those reported by Macedo and Malcata (1997a) for Serra da Estrela cheese. As expected, proteolysis in terms of WSN contents proceeded similarly in the experimental cheeses with regard to that monitored in control cheeses. This is so because the components of WSN in Serra da Estrela cheese are mainly accounted for by nitrogen compounds, which are produced via protein hydrolysis brought about by the thistle flower - which is known to be highly proteolytic (Sousa and Malcata, 1996a); therefore, most of the inventory of the WSN of this cheese is likely the result of breakdown of caseins effected by cardosins, rather than by lactic acid bacteria (Sousa and Malcata, 1996b; Macedo and Malcata, 1997b; Macedo et al., 2000). Additionally, it is much more difficult to check for a possible contribution by the proteinases of the lactic acid bacteria, unless they were present in extremely high numbers (which was not the case) or exhibited strong specific caseinolytic activities (which was also not the case) (Macedo and Malcata, 1999). On the other hand, the intentional addition of $L$. lactis or Lb. plantarum increased significantly the proteolysis in Serra da Estrela cheese in terms of $2 \%$ TCASN and $12 \%$ TCASN contents. The ripening agents that may be implicated with generation of nitrogen compounds included in $2 \%$ TCASN are peptidases released from viable or lysed lactic acid bacteria, and the unspecific proteases of the thistle flower to a much lesser extent (Yvon et al., 1989; Sousa and Malcata, 1996b), whereas the compounds included in $12 \%$ TCASN are released only by peptidases freed by lactic acid bacteria upon lysis (Sousa and Malcata, 1996b) - which reach the death phase by ca. 42 days. The low content values can, nevertheless, be explained by the intrinsically low dipeptidase and aminopeptidase activities of the cell-free extracts of the wild strains of lactic acid bacteria isolated from Serra da Estrela cheese (Macedo et al., 2000, 2002), which are further constrained by the adverse conditions prevailing in cheese, e.g. considerable concentration of salt, low water activity and low temperature.

In sensory terms, the cheeses manufactured with lactic acid bacteria intentionally added were somewhat lower scored than the control cheeses. This realization is accounted for mainly by: (i) lower scores attributed to the rind and shape in experimental cheeses (which cannot be fully rationalized); (ii) the more acid flavor (due to the lower $\mathrm{pH}$ values); and (iii) the more bitter flavor (associated with higher contents of $2 \%$ and $12 \%$ TCASN-which is consistent with the observation that peptides with hydrophobic character tend to be released in ovine cheese to a higher extent than their hydrophylic counterparts; Sousa and Malcata, 1996b).

Finally, one concludes that the addition on purpose of L. lactis and/or Lb. plantarum in Serra da Estrela cheese brings about the benefit of reducing the numbers of Enterobacteriacea, but at the expense of having more acid and bitter cheeses.

\section{Acknowledgements}

To the FCT (Portugal) Programs PRAXIS XXI, for the postdoctoral fellowship granted to Angela C. Macedo (BPD/20158/99), and POCTI, for funding via project MICROCHEESE (POCTI/1999/BIO/36197). The authors are indebted to the members of the technical board of ANCOSE, for their cooperation in supervising the local manufacture of the experimental cheeses according to the design presented, and in transporting them to our laboratory premises.

\section{References}

Anonymous, 1985. Diário da República. III-Série. No. 30/ 85 de 5 de Fevereiro. Norma Portuguesa 1922. Imprensa Nacional, Casa da Moeda, Lisbon, Portugal.

Drake, M.A., Boylston, T.D., Spence, K.D., Swans, B.G., 1996. Chemical and sensory effects of Lactobacillus adjunct in Cheddar cheese. Food Res. Int. 29, 381-387.

El Soda, M., Madkor, S.A., Tong, P.S., 2000. Adjunct cultures: recent developments and potential significance to the cheese industry. J. Dairy Sci. 83, 609-619.

Gaya, P., Medina, M., Bautista, L., Nuñez, M., 1988. Influence of lactic starter inoculation, curd heating and ripening temperature on Staphylococcus aureus behavior in Manchego cheese. Int. J. Food Microbiol. 6, 249-257.

González-Crespo, J., Mas, M., 1993. Estudio del empleo de fermentes iniciadores autóetones en la elaboración de queso de calsa de pasta prensada, con leche pasteurizade. Alimentaria 243, 51-53.

IDF, 1993. Milk. Determination of nitrogen content. Bull. Int. Dairy Fed. Standard 20B, International Dairy Federation, Brussels, Belgium.

Lee, B.H., Laleye, L.C., Simard, R.E., Holly, R.A., Emmys, D.B., Giro, R.N., 1990. Influence of homofermentative lactobacilli on physicochemical and sensory properties of Cheddar cheese. J. Food Sci. 55, 386-390. 
Litopoulou-Tzanetaki, E., Tzanetakis, N., Vafopoulou-Mastrojiannaki, A., 1993. Effect of the type of lactic acid bacteria on microbiological, chemical and sensory characteristics of Feta cheese. Food Microbiol. 10, 31-41.

Macedo, A.C., Malcata, F.X., 1997a. Secondary proteolysis in Serra cheese during ripening and throughout the cheese-making season. Z. Lebensm. Unters. Forsch. A 204, 173-179.

Macedo, A.C., Malcata, F.X., 1997b. Role of native microflora in proteolysis and lipolysis of Serra cheese: preliminary screening. Z. Lebensm. Unters. Forsch. A 205, 25-30.

Macedo, A.C., Malcata, F.X., 1999. Actividade caseinolítica de bactérias lácticas isoladas do queijo Serra da Estrela [Caseinolytic activity of lactic acid bacteria isolated from Serra da Estrela cheese]. Congresso Nacional de Microbiologia, Luso, Portugal: December 1-4. Abstract P76 in MICRO'99 - Program and Abstracts, p. 148.

Macedo, A.C., Malcata, F.X., Oliveira, J.C., 1993. The technology, chemistry and microbiology of Serra cheese: a review. J. Dairy Sci. 76, 1725-1739.

Macedo, A.C., Malcata, F.X., Hogg, T.A., 1995. Microbiological profile in Serra ewe's cheese during ripening. J. Appl. Bacteriol. 79, 1-11.

Macedo, A.C., Costa, M.L., Malcata, F.X., 1996. Assessment of proteolysis and lipolysis in Serra cheese: effects of axial location, ripening time, and lactation season. Lait 76, 363-370.

Macedo, A.C., Vieira, M., Poças, R., Malcata, F.X., 2000. Peptide hydrolase system of lactic acid bacteria isolated from Serra da Estrela cheese. Int. Dairy J. 10, 769-774.

Macedo, A.C., Tavares, T.G., Malcata, F.X., 2002. Purification and characterization of an intracellular aminopeptidase from a wild strain of Lactobacillus plantarum isolated from traditional Serra da Estrela cheese. Enzyme Microb. Technol. 32, 41-48.
Mendia, C., Ibañez, F.J., Torre, P., Barcina, Y., 2000. Effect of pasteurization and use of a native starter culture on proteolysis in a ewe's milk cheese. Food Control 11, 195-200.

Ortigosa, M., Bárcenas, P., Arizcun, C., Pérez-Elortondo, F., Albisu, M., Torre, P., 1999. Influence of the starter culture on the microbiological and sensory characteristics of ewe's cheese. Food Microbiol. 16, 237-247.

Puchades, R., Lemieux, L., Simard, R.E., 1989. Evolution of free amino acids during ripening of Cheddar cheese containing added Lactobacillus strains. J. Food Sci. 54, 885-888.

Rash, K.E., Kosikowski, F.V., 1981. Influence of lactic acid starter bacteria on enteropathogenic Escherichia coli in ultrafiltrationprepared Camembert cheese. J. Dairy Sci. 65, 537-543.

Rutzinski, J.L., Marth, E.H., Olson, N.F., 1979. Behavior of Enterobacter aerogenes and Hafnia species during the manufacture and ripening of Camembert cheese. J. Food Prot. 42, 790-793.

Sousa, M.J., Malcata, F.X., 1996a. Effects of processing conditions on the caseinolytic activity of crude extracts of Cynara cardunculus $\mathrm{L}$. Food Sci. Technol. Int. 2, 255-263.

Sousa, M.J., Malcata, F.X., 1996b. Influence of pasteurization of milk and addition of starter cultures on protein breakdown in ovine cheeses manufactured with extracts from flowers of Cynara cardunculus. Food Chem. 57, 549-556.

Tavaria, F.K., Malcata, F.X., 1998. Microbiological characterization of Serra da Estrela cheese throughout its AOP region. J. Food Prot. 6, 601-607.

Yvon, M., Chabanet, C., Pélissier, J.P., 1989. Solubility of peptides in trichloroacetic acid (TCA) solutions. Int. J. Peptide Protein Res. 29, 166-171. 